\title{
Application of Nursing Quality Index Management in Reducing the Infection of Tunnel-Cuffed Hemodialysis Catheter
}

\author{
Huan Liu' ${ }^{1}$, Folan Li ${ }^{1}$, Fanna Liu ${ }^{2 *}$, Yu Chen ${ }^{2 *}$ \\ ${ }^{1}$ Blood Purification Center, The First Affiliated Hospital of Jinan University, Guangzhou, China \\ ${ }^{2}$ Nephrology Department, The First Affiliated Hospital of Jinan University, Guangzhou, China \\ Email:*1139795771@qq.com
}

How to cite this paper: Liu, H., Li, F.L., Liu, F.N. and Chen, Y. (2020) Application of Nursing Quality Index Management in Reducing the Infection of Tunnel-Cuffed Hemodialysis Catheter. Open Journal of Urology, 10, 84-92.

https://doi.org/10.4236/oju.2020.104010

Received: February 17, 2020

Accepted: March 24, 2020

Published: March 27, 2020

Copyright $\odot 2020$ by author(s) and Scientific Research Publishing Inc. This work is licensed under the Creative Commons Attribution International License (CC BY 4.0).

http://creativecommons.org/licenses/by/4.0/

\begin{abstract}
Objective: To explore how the nursing quality management reduces the infection of tunneled-cuffed hemodialysis catheter (TCC). Methods: The TCC infection rate from January $1^{\text {st }}$ to December $31^{\text {th }}$ was used as the baseline data, and the TCC infection rate from January 2014 to December 2017 was used for annual comparison. Through the nursing quality index management mode, the TCC infection rate was compared quarterly, annually and year by year by taking the measures of joint ward checking, optimizing nursing process, analyzing the root cause of infection cases and formulating countermeasures. Results: The Centre has been implementing the management of nursing quality indicators since 2014. TCC infection rate is an important part of Quality of Nursing Index Management. The comparison between 2013 and $2014\left(\mathrm{X}^{2}=4.20, \mathrm{P}=0.04\right)$ was $\mathrm{P}<0.05$, which was statistically significant. TCC infection rate dropped from $1.19 \%$ in 2013 to $0.51 \%$ in 2017 . The number of TCC patients and indwelling catheter days increased year by year from 2013 to 2017, but the rate of TCC infection decreased year by year. Conclusion: The nursing quality index management can effectively reduce the incidence of TCC infection.
\end{abstract}

\section{Keywords}

Nursing Quality Index, Hemodialysis, Catheter-Associated Infection, CRI

\section{Introduction}

In China, the number of maintenance hemodialysis (MHD) patients has increased dramatically. According to the statistics of the National Blood Purifica- 
tion Case Information Registration System, the growth rate of MHD patients in China from 2011 to 2014 was as high as $44.9 \%$, ranking the second in the world and the fastest in the world [1]. Vascular access is the lifeline of MHD patients. Central venous catheter as a vascular access is widely used in clinical dialysis, but catheter related infection (CRI) is one of the main complications and the main causes of the catheter dysfunction [2]. It has serious influence to patients with hemodialysis, resulting in patients extending the hospitalization. Severe cases can cause deaths [3]. In order to reduce the occurrence of CRI and reduce the pain and economic burden of patients, the center applied the nursing quality index management to the management of CRI and achieved better results. The nursing quality index is the quantitative measurement of nursing quality, the tool for evaluating clinical care quality and care activities. Being quantitative, effective and objective is the basic characteristic of the nursing quality Index [4]. A domestic study has shown that the management of nursing quality index can improve the quality of hemodialysis. But on the CRI, only two quarters of data were compared. It was not statistically significant, however, the indicators fell significantly. The research time is short and there are some limitations [5].

\section{Materials and Methods}

\subsection{General Information}

All the cases were selected from hemodialysis patients using TCC in our center from 2013 to 2017. There were a total of 434 cases, aged from 6 to 93 years old. The primary diseases were hypertensive nephropathy, diabetic nephropathy, chronic glomerulonephritis, cystic nephropathy, obstructive nephropathy and so on. The TCC detention period was from 2 months to 7 years. Catheterization was performed in 426 cases of the right internal jugular vein, 7 cases of the left internal jugular vein and 1 case of the right femoral vein. Hemodialysis was performed three times a week for 4 hours each time.

\subsection{General Information of the 434 Patients}

The basic information of the 434 patients was as follows: 217 males and $217 \mathrm{fe}$ males, with an average age of $61.47 \pm 16.56$. The original diseases - there were 141 cases of hypertensive nephropathy (32.5\%), 105 cases of diabetic nephropathy (24.2\%), 56 cases of chronic glomerulonephritis (12.9\%), 27 cases of cystic nephropathy (6.2\%), 63 cases of obstructive nephropathy (14.5\%), 13 cases of nephrotic syndrome (3.0\%), 4 cases of acute kidney injury (0.9\%), and 25 cases of other primary diseases (5.8\%). The average catheter detention days were 180 \pm 325.077. See Table 1 .

\subsection{Basis for Definitions of Catheter-Related Infection}

1) Catheter outlet infection: infection within $2 \mathrm{~cm}$ of catheter outlet. 2) Duct tunnel infection: Infection within the subcutaneous tunnel of the catheter more than $2 \mathrm{~cm}$ away from the outlet. 3) Catheter related blood stream infection 
Table 1. Basic information of patients $(\mathrm{N}=434)$.

\begin{tabular}{cc}
\hline Project & Value $(\mathrm{N}=434)$ \\
Age (years old) & $61.47 \pm 16.56$ \\
Gender & $217(50 \%)$ \\
Male & $217(50 \%)$ \\
Female & \\
Original diseases & $141(32.5 \%)$ \\
Hypertensive nephropathy & $105(24.2 \%)$ \\
Diabetic Nephropathy & $56(12.9 \%)$ \\
Chronic glomerulonephritis & $27(6.2 \%)$ \\
Cystic nephropathy & $63(14.5 \%)$ \\
Obstructive nephropathy & $13(3.0 \%)$ \\
Nephrotic syndrome & $4(0.9 \%)$ \\
Acute kidney injury & $25(5.8 \%)$ \\
Others* & $180 \pm 325.077$ \\
Catheter Detention (days) &
\end{tabular}

Note: ${ }^{*}$ Others include drug-induced renal damage, membranous nephropathy, multiple myeloma, lupus nephritis, hemolytic uremic syndrome, ANCA-associated vasculitis, hepatitis b-associated nephritis, and purpura nephritis.

(CRBSI): Bacteremia or septicemia caused by a partial infection in the lumen or blood vessel that spreads into the blood stream [6].

\subsection{Two Methods Were Used to Calculate the Annual TCC Infection Rate}

1) The internationally accepted 1000-day rate of infection was calculated as = infection cases/catheter days $\times 1000$. 2) The catheter infection rate was calculated by comparing the number of infections with the total number of patients = infections/patients $\times 100$.

\subsection{Research Methods}

Application of Quality of Nursing Index Management

1) The quality index management was implemented in the first quarter of 2014, and establishment of a Quality Management Team, with the head nurse as the group leader and the nursing core staff as the team members. TCC experts in the group are responsible for statistics and analysis of infection rates in 2013.

2) TCC registration forms were developed from 2014. The nurses in each shift recorded and transferred the abnormal situation of TCC in the shift. The TCC specialist executed timely integrated medical checking to TCC infection cases. They developed and implemented treatment and nursing plan together. TCC specialist collected data every quarter, controlled the nursing quality of the TCC, analyzed the problems existing in the record, and found out the root cause of the infection (from people, machine, material, method or checking). The specialist 
would also personalize solutions to problems, train the nurse how to solve common problems, optimize the procedure and supervise the implementation.

3) Studies have shown that catheter infection is related to catheter interface contamination, skin bacterial transitional contamination of puncture site, hemoperfusion contamination, catheter material, bacterial biofilm, internal characteristics of pathogens and other factors [7] [8]. Studies have shown that cluster nursing can effectively reduce the incidence of catheter infection [9]. Since 2014, our department has continuously revised and optimized the guidelines for catheter opening and sealing and catheter dressing change, implemented personalized dressing change procedures for patients with different conditions, bound them into books and organized medical staff in the department to conduct training and learning.

4) For TCC patients, guidance was offered to them on infect control at home. They could choose to wrap plastic wrap around the shoulder of the catheter during shower to cover the entire catheter or clean the covered area after shower or put the external part of the catheter into the anal bag, with the adhesive layer of the anal bag around the catheter mouth, remove the disposable anal bag after shower, and then re-fix the exposed part of the catheter in front of the chest wall. Lectures on catheter maintenance were given to patients no less than twice a year, and special guidance was given by the nurse in charge of each dialysis.

5) Training of nursing personnel: all the new and advanced nurses received the theoretical and operational training of dialysis catheter opening, dressing changing and sealing, and shall not conduct the above operations independently before passing the examination of operation and theory. Unnecessary opening times of catheter ports during dialysis were avoided. For poor catheter flow and reverse connection of arteriovenous ports, nurses were required to perform hand hygiene, wear sterile gloves to separate catheter and blood line catheter, and reduce exposure time of catheter ports. There would be blood scab formation at the thread of the catheter after the reverse connection. It was required that the nurse should use disinfectant gauze to clean the blood scab when getting off. After there was no blood scab left, the sterile disinfection process should be carried out. They had to put the sterile plug to protect the catheter port, preventing blood scabs from entering the catheter and reducing the risk of infection.

6) To find out the regularity or seasonality of TCC infection. From statistical records, we found that each year in the 3rd quarter TCC infection rate had a rising trend. Through the integration of medical ward inspection, analysis and discussion, we found that the third quarter in Guangzhou (7 September) was usually hot and the stay-home patients would easily sweat. Guangzhou people like to take shower, and the catheter dressing exposed to water. We selected different dressings for different patients. For patients with a certain level of knowledge and good learning ability, we guided them to change the dressing for the catheter at home, and the catheter infection was better controlled.

7) Nursing quality indicator management not implemented in 2013. Accor- 
dingly, following the implementation of improvement measures in 2014, The TCC infection rate in 2013 was used as the baseline data and compared with the annual TCC infection rate from 2014 to 2017. From 2013, pairwise comparison was conducted for the infection rate every two years. TCC experts are responsible for this statistical work.

\subsection{Statistical Methods}

SPSS 23.0 Software was used for statistical analysis of the data, and the counting data were expressed as rate. $\mathrm{X}^{2}$ test was used, and $\mathrm{P}<0.05$ was considered as statistically significant.

\section{Results}

\subsection{Distribution of Pathogenic Bacteria}

From 2013 to 2017, there were 60 cases of catheterization infection in TCC patients, among which pathogenic bacteria were detected in 13 patients, with a positive detection rate of $21.67 \%$. Among them, there were 5 cases of Staphylococcus aureus, 1 case of staphylococcus epidermidis, 1 case of gram-positive cocci, 1 case of staphylococcus vorchii, 1 case of acinetobacter baumannii, 1 case of colorobacillus denitrifying, 1 case of sarrella mucilis, 1 case of staphylococcus cephalus and 1 case of pseudomonas aeruginosa. This result is similar as the report of Yuhong Pang and Jun Wang et al. in China, as well as the reports abroad [10] [11] [12]. Staphylococcus aureus remains the most common infectious pathogen.

\subsection{Statistical Results}

The number of TCC patients and indwelling catheter days increased year by year from 2013 to 2017, while the total infection rate decreased, as shown in Table 2. As shown in Table 2, after comparison, the infection rate of TCC showed a decreasing trend $\left(\mathrm{X}^{2}=11.34, \mathrm{P}=0.023\right)$. From 2013 , pairwise comparison was conducted for the infection rate every two years. The comparison between 2013 and $2014\left(\mathrm{X}^{2}=4.20, \mathrm{P}=0.04\right)$ was $\mathrm{P}<0.05$, which was statistically significant. Compare the other years in pairs. The comparison between 2014 and $2015\left(\mathrm{X}^{2}=\right.$ $0.00, \mathrm{P}=0.10), 2015$ and $2016\left(\mathrm{X}^{2}=0.03, \mathrm{P}=0.85\right), 2016$ and $2017\left(\mathrm{X}^{2}=1.35, \mathrm{P}\right.$ $=0.25)$ result was $P>0.05$, which was not statistically significant.

\section{Discussion}

TCC infection rate is one of the important indicators to measure the quality of hemodialysis, and the incidence of CRBSI has been reported to be on the rise, which is one of the common complications of maintenance hemodialysis patients [13]. There have been many clinical reports on the use of antimicrobial agents to seal tubes to prevent catheter-related infections, but it is easy to cause bacterial resistance, increase the risk of fungal infection, and increase the economic burden of patients [14] [15]. Non-antimicrobial agents have also been 
Table 2. The infection of TCC patients in this center.

\begin{tabular}{|c|c|c|c|c|c|c|c|c|c|c|}
\hline \multirow[b]{2}{*}{ Year } & \multirow[b]{2}{*}{$\begin{array}{l}\text { Patient } \\
\text { Cases }\end{array}$} & \multirow[b]{2}{*}{$\begin{array}{l}\text { Detention } \\
\text { days }\end{array}$} & \multicolumn{2}{|c|}{ Total infection } & \multicolumn{2}{|c|}{ Catheter outlet infection } & \multicolumn{2}{|c|}{ Duct tunnel infection } & \multicolumn{2}{|c|}{ CRBSI } \\
\hline & & & $\begin{array}{c}\text { Infection } \\
\text { cases n (\%) }\end{array}$ & $\begin{array}{c}1000 \text {-day rate } \\
\text { of infection } \\
(\% \text { ) }\end{array}$ & $\begin{array}{c}\text { Infection } \\
\text { cases n (\%) }\end{array}$ & $\begin{array}{c}\text { 1000-day rate } \\
\text { of infection } \\
(\% \text { ) }\end{array}$ & $\begin{array}{c}\text { Infection } \\
\text { cases n (\%) }\end{array}$ & $\begin{array}{c}1000 \text {-day rate } \\
\text { of infection } \\
(\% \text { ) }\end{array}$ & $\begin{array}{c}\text { Infection } \\
\text { cases n (\%) }\end{array}$ & $\begin{array}{c}1000 \text {-day rate } \\
\text { of infection } \\
(\%)\end{array}$ \\
\hline 2013 & 41 & 7553 & $9(21.95)$ & 1.19 & $7(77.78)$ & 0.93 & $0(0.00)$ & 0.00 & $2(22.22)$ & 0.26 \\
\hline 2014 & 101 & 10314 & $8(7.92)$ & 0.78 & $7(87.50)$ & 0.68 & $0(0.00)$ & 0.00 & $1(12.50)$ & 0.10 \\
\hline 2015 & 189 & 16110 & $15(7.94)$ & 0.93 & $10(66.67)$ & 0.62 & $0(0.00)$ & 0.00 & $5(33.33)$ & 0.31 \\
\hline 2016 & 215 & 21123 & $16(7.44)$ & 0.76 & $10(62.50)$ & 0.47 & $1(6.25)$ & 0.05 & $5(31.25)$ & 0.24 \\
\hline 2017 & 247 & 23408 & $12(4.86)$ & 0.51 & $9(75.00)$ & 0.38 & $1(8.33)$ & 0.04 & $2(16.67)$ & 0.09 \\
\hline
\end{tabular}

used to seal catheters to control catheter-related bacteremia [16]. Since the implementation of quality index management of hemodialysis nursing in our dialysis center, root cause analysis has been conducted for TCC infection cases. Sensitive antibiotics have been selected for sealing for more than 3 weeks for CRBSI patients according to etiological data, and the compatibility of antibiotics and heparin has been noted. It has been reported in the literature that the extending for the prophylaxis of antibiotic sealing tube to $1-2$ weeks can consolidate the curative effect, and prophylactic antibiotic sealing tube is not recommended [17].

Hypertensive nephropathy has occupied the first place in the primary disease in our center. Foreign studies have shown that hypertension is an independent risk factor for catheter infection, and the related reasons are as follows: hypertension is often associated with diabetes or atherosclerosis, increasing the risk of infection [18]; some antihypertensive drugs may help to increase the risk of infection [19]; hypertension affects capillaries in the skin and increases bacterial colonization of catheters [20]. Therefore, the joint management of hypertension and its complications has become a top priority. For patients with hypertension, the focus of nursing in dialysis is to monitor the changes of blood pressure on time and focus on the changes of patients' mental state; strengthen home blood pressure health education for patients; distribute home blood pressure monitoring record books; teach patients to measure blood pressure correctly, record accurately, take medicine on time, control blood pressure within the ideal range; delay the occurrence or development of complications, in order to reduce the incidence of catheterization infection. The patient was taught to observe the dressing in the catheterization place and the surrounding skin condition correctly at home, find the abnormal situation in time, and seek medical advice in time.

The prevention of catheter-related infections is not only a nursing problem, but also a joint effort of three parties. Studies have shown that in Nursing Quality Index Management, certain effects have been achieved in reducing the rate of catheter infection [21]. CRBSI is closely related to aseptic technique operation, disinfection isolation and hand hygiene of medical staff in hemodialysis room 
[22]. The first is aseptic operation during catheterization by the physician, followed by catheter nursing during each dialysis session, and then catheter nursing at home for the patient. TCC catheterization was performed in a sterile operating room, so the emphasis was on catheter nursing during each dialysis session and patient nursing at home. Each dialysis nursing is influenced by three factors: environment, process and nurse operation. In the case of poor indoor ventilation and crowded personnel, if there are diseased primary microorganisms in the air, the pathogens can be ejected along with the droplets through conversation, cough and sneeze, so as to cause infection in susceptible people [23]. Therefore, the center does not leave accompanying people on, off, and when opening or sealing the tube, and patients with catheters must wear disposable masks. Clearing the field between the two classes of patients, opening the window for ventilation and reducing the number and activity of indoor staff, reduces the concentration of pathogens in the air, and thus reduces the infection rate. The most difficult factor to control in these three aspects is the patient side, so we value proper in-home catheter nursing for patients. If patients do not know self-protection and self-management, catheter infection will be difficult to effectively control.

This study has some limitations. The number of single center cases is less. Target management of indicators lacking universally accepted regional standards. This study shows that, TCC infection is difficult to avoid, implement quality index management, find out the root cause of infection, constantly optimize the catheter nursing process, train nurses and patients, the infection rate of TCC can be controlled. In this study, the types of pathogenic bacteria are similar to the results of domestic and foreign studies, but the detection rate of pathogenic bacteria is not high, this part needs to be further studied.

\section{Conflicts of Interest}

The authors declare no conflicts of interest regarding the publication of this paper.

\section{References}

[1] Sun, X.F. (2016) Hypertension Management in Hemodialysis Patients. Chinese Journal of Integrated Traditional Chinese and Western Medicine Nephropathy, 17, 189-191.

[2] Yang, Y., Song, X.Q., Wang, X.Y., et al. (2007) Analysis of Infection with Long-Term Tunneled Catheter in Deep Vein of Hemodialysis. Journal of Integrated Traditional Chinese and Western Medicine, 16, 464-465.

[3] Souweine, B., Lautrette, A., Gruson, D., et al. (2015) Ethanol Lock and Risk of Hemodialysis Catheter Infection in Critically Ill Patients. A Randomized Controlled Trial. The American Journal of Respiratory and Critical Care Medicine, 191, 1024-1032. https://doi.org/10.1164/rccm.201408-1431OC

[4] Podgomey, K. (1996) Development of Nursing Quality Indicators. Journal of Advanced Nursing, 16, 858-864.

[5] Gao, J.L., Xin, X., Che, W.F., et al. (2018) Application of Nursing Quality Index to 
Improve the Quality of Hemodialysis. Health Quality Management in China, 25, 67-70.

[6] Jin, Q.Z., Wang, Y.Z., Ye, C.Y., et al. (2019) Vascular Pathway Working Group of Chinese Hospital Association Blood Purification Center Branch. Chinese Blood Dialysis System Expert Consensus (the Second Edition) of the Chinese Blood Purification, 18, 365-381.

[7] Lou, H.Q., Jin, Y.Y., Xu, G.J., et al. (2014) Analysis of Factors and Preventive Measures for Infection of Blood Purification Catheter. Chinese Journal of Nosocomial Infectiology, 24, 1184-1185.

[8] Lok, C.E., Thumma, J.R., McCullough, K.P., et al. (2014) Catheter Related Infection and Septicemia: Impact of Seasonality and Modifiable Practices from the DOPPS. Seminars in Dialysis, 27, 72-77. https://doi.org/10.1111/sdi.12141

[9] Xia, L.P., Bian, L.Y., Tan, S.Y., et al. (2015) An Empirical Study on the Prevention of Catheter-Related Infection in Patients with Severe Craniocerebral Injury by Cluster Intervention Strategy. Chongqing Medical Journal, 44, 3845-3846.

[10] Pang, Y.H., Zhao, J.M., Chen, K.Z., et al. (2016) Pathogen Changes and Risk Factors Analysis of Temporary Central Venous Catheter Infection. Chinese Journal of Blood Purification, 15, 315-318.

[11] Wang, J., Qi, H.L., Jiang, W., et al. (2014) Retrospective Study on Temporary Central Venous Catheter-Related Infections in Hemodialysis Patients. Chinese Journal of Blood Purification, 13, 401-404.

[12] Sedlacek, M., Gemery, J.M., Cheung, A.L., et al. (2007) Aspirin Treatment Is Associated with a Significantly Decreased Risk of Staphylococcus aureus Bacteremia in Hemodialysis Patients with Tunneled Catheters. American Journal of Kidney Diseases, 49, 401-408. https://doi.org/10.1053/j.ajkd.2006.12.014

[13] Bouza, E., Rojas, L., Guembe, M., et al. (2014) Predictive Value of Superficial Cultures to Anticipate Tunneled Hemodialysis Catheter Related Bloodstream Infection. Diagnostic Microbiology and Infectious Disease, 78, 316-319. https://doi.org/10.1016/j.diagmicrobio.2013.12.008

[14] Qin, D.P., Zhong, X.S., Chen, W.X., He, X.X., Hu, J.G. and Zheng, Y.Y. (2016) Application of Amika Star Sealed Tube in Tunnel and Polyester Sleeve Catheter of Hemodialysis Patients. Blood Purification of China, 15, 116-118.

[15] Dogra, G.K., Herson, H., Hutchison, B., et al. (2002) Prevention of Tunneled Hemodialysis Catheter Related Infections Using Catheter Restricted Filling with Gentamicin and Citrate: A Randomized Controlled Study. Journal of the American Society of Nephrology, 13, 2133-2139.

https://doi.org/10.1097/01.ASN.0000022890.29656.22

[16] Hu, Z.F. and Xiao, H.Q. (2014) The Research Progress of Non-Antibiotic Seal Technology in the Prevention and Treatment of Chronic Catheter Related Bacteriemia in Hemodialysis. Chinese Blood Purification, 13, 31-33.

[17] Mermel, L.A., Allon, M., Bouza, E., et al. (2009) Clinical Practice Guidelines for the Diagnosis and Management of Intravascular Catheter-Related Infection: $2009 \mathrm{Up}$ date by the Infectious Diseases Society of America. Clinical Infectious Diseases, 49, 1-45. https://doi.org/10.1086/599376

[18] Gress, T.W., Nieto, F.J., Shahar, E., et al. (2000) Hypertension and Antihypertensive Therapy as Risk Factors for Type 2 Diabetes Mellitus. Atherosclerosis Risk in Communities Study. The New England Journal of Medicine, 342, 905-912. https://doi.org/10.1056/NEJM200003303421301

[19] Mukamal, K.J., Ghimire, S., Pandey, R., et al. (2010) Antihypertensive Medications 
and Risk of Community Acquired Pneumonia. Journal of Hypertension, 28, 401-405. https://doi.org/10.1097/HJH.0b013e3283330948

[20] Antonios, T.F., Rattray, F.M., Singer, D.R., et al. (2003) Rarefaction of Skin Capillaries in Normotensive Offspring of Individuals with Essential Hypertension. Heart, 89, 175-178. https://doi.org/10.1136/heart.89.2.175

[21] Zou, Y.M., Wu, Y.F. and Li, J. (2013) Effect Analysis and Nursing of Cluster Nursing in Prevention of Hemodialysis Catheter-Related Bloodstream Infection. Journal of Nurses, 28, 665-667.

[22] Abdel-Rahman, E.M., Turgut, F., Turkmen, K., et al. (2011) Falls in Elderly Hemodialysis Patients. QJM, 104, 829-838. https://doi.org/10.1093/qjmed/hcr108

[23] Fu, H. and Duan, G.C. (2004) Preventive Medicine. People's Medical Publishing House, Beijing, 29-36. 